\title{
Clinical Manifestations of Allergic Rhinitis
}

Nina Lakhani ${ }^{1}$, Michelle North ${ }^{1,2}$ and Anne K. Ellis ${ }^{1,2}$

${ }^{1}$ Department of Medicine, Queen's University, Kingston, ON, Canada

${ }^{2}$ Department of Biomedical and Molecular Sciences, Queen's University, Kingston, ON, Canada

\begin{abstract}
Objective: To provide a concise review of the classification, nasal manifestations, non-nasal manifestations, and quality of life impact of allergic rhinitis.

Data sources: MEDLINE (PubMed) search using the terms allergic rhinitis, combined with the terms perennial, seasonal, non-nasal, symptoms and quality of life.

Study selection: Human studies and reviews published in the English language.

Results: The prevalence of allergic rhinitis is increasing worldwide. Symptoms include rhinorrhea, sneezing, obstruction of the nasal passages, and may be underestimated by patients. Traditionally, allergic rhinitis has been classified as perennial or seasonal; however, the Allergic Rhinitis and its Impact on Asthma (ARIA) classification may provide a better description of individual symptoms. Complications of allergic rhinitis include nasal polyps and bacterial sinusitis and comorbid conditions include asthma, allergic conjunctivitis and atopic dermatitis. The list of potential differential diagnoses is extensive, but important not to miss are the rare presentations of nasopharyngeal tumors, Wegener's Granulomatosis and sarcoidosis. Epidemiological studies have shown a reduction in quality of life in patients suffering from allergic rhinitis and new tools have allowed for better assessments of the impact of illness on patient's lives.
\end{abstract}

Conclusion: Patients with allergic rhinitis can experience a wide range of troublesome clinical symptoms, which are often under recognized and underreported causing a delay in seeking medical attention and subsequent reduction in health related quality of life.

Keywords: Allergic rhinitis; Allergy; Rhinitis; Atopy; Seasonal; Perennial; Nasal; Quality of life

\section{Introduction}

Epidemiological data suggests that the prevalence of allergic rhinitis is increasing worldwide [1]. Despite this, symptoms of allergic rhinitis are often underestimated by patients or are perceived as 'normal'. Surveys of allergy sufferers across the United States of America have reported up to $61 \%$ of individuals being tolerant or able to ignore symptoms of allergic rhinitis, but over $80 \%$ of these individuals reported allergic symptoms altering their quality of life during allergy season [2]. Low rates of recognition, underreporting and delay in seeking medical attention often lead to altered quality of life for patients and the impact on work productivity and school performance is often under recognized [3]. This review focuses on the classification, nasal manifestations, non-nasal manifestations, and quality of life impact of allergic rhinitis.

\section{Classification of Allergic Rhinitis}

Standard classifications of allergic rhinitis have undergone significant modifications over recent decades. Traditionally, allergic rhinitis was classified based on allergen exposure and thus was either considered perennial, with symptoms occurring year round, or seasonal, with symptoms occurring at a particular time of the year [4]. Perennial symptoms have conventionally been thought to be due to indoor allergens, most commonly dust mite, cockroach and moulds. Seasonal symptoms were thought to be due to outdoor allergens, such as pollens. The challenge with following the standard method of classification lies in the appropriate categorization of patients with respect to severity and duration of their disease. Additionally, from a therapeutic perspective, differentiating seasonal and perennial symptoms often proves to be difficult as many patients are polysensitized to both seasonal and perennial allergens [5]. Seasonal allergens alone and in combination may cause year-round symptoms and perennial allergens may only cause symptoms at particular times of the year.

The Allergic Rhinitis and its Impact on Asthma (ARIA) classification was first proposed in 1999 as a tool to provide a better description of allergic rhinitis giving consideration to both severity and duration of symptoms [6]. This classifies rhinitis symptoms as "intermittent" or "persistent" based on number of days per week and consecutive weeks that patients are affected by symptoms (Figure). Severity is quantified as 'mild' or 'moderate-severe' on the basis of self-perceived degree of symptomatology, as well as patient quality of life (Figure). The ARIA classification has been validated in regards to severity scoring and quality of life indices with the ability to differentiate two distinct states of $\mathrm{Al}$ lergic Rhinitis (mild vs. moderate/severe) and impact on daily life [5].

Other means of quantifying symptoms include severity scoring indexes, including the Rhinoconjunctivitis Quality of Life Questionnaire (RQLQ), Total 4-Symptom Score (T4SS) and the Visual Analogue Score (VAS 0-100 mm). These tools have been utilized to validate existing classification systems [2] and may further aid clinicians to determine effectiveness of their treatments.

*Corresponding author: Dr. Anne K. Ellis, MD, Doran 1, Kingston General Hospital, 76 Stuart Street, Kingston, Ontario, Canada K7L 2V7, Tel: (613) 548-2336; Fax: (613) 5336796; E-mail: ellisa@queensu.ca

Received April 26, 2012; Accepted June 13, 2012; Published June 18, 2012

Citation: Lakhani N, North M, Ellis AK (2012) Clinical Manifestations of Allergic Rhinitis. J Aller Ther S5:007. doi:10.4172/2155-6121.S5-007

Copyright: ( 2012 Lakhani N, et al. This is an open-access article distributed unde the terms of the Creative Commons Attribution License, which permits unrestricted use, distribution, and reproduction in any medium, provided the original author and source are credited. 


\begin{tabular}{|c|c|}
\hline $\begin{array}{c}\text { Intermittent } \\
\text { Symptoms } \\
<4 \text { days per week } \\
\text { or }<4 \text { consecutive weeks }\end{array}$ & $\begin{array}{c}\text { Persistent } \\
\text { Symptoms } \\
>4 \text { days per week } \\
\text { and }>4 \text { consecutive weeks }\end{array}$ \\
\hline $\begin{array}{l}\text { Mild } \\
\text { all of the following: } \\
\text { 1) Normal sleep } \\
\text { 2) No impairment of } \\
\text { daily activities } \\
\text { 3) No impairment of } \\
\text { work/school } \\
\text { 4) Symptoms present } \\
\text { but not troublesome }\end{array}$ & $\begin{array}{l}\text { Moderate - Severe } \\
\text { one or more of: } \\
\text { 1) Disturbed sleep } \\
\text { 2) Impairment of } \\
\text { daily activities } \\
\text { 3) Impairment of } \\
\text { work/school } \\
\text { 4) Troublesome } \\
\text { Symptoms }\end{array}$ \\
\hline
\end{tabular}

Classification of allergic rhinitis, adapted from Bousquet et al. [7]. Classification based on the intermittent or persistent and moderate or severe nature of symptoms

Figure: Classification of allergic rhinitis.

\section{Nasal Manifestations}

Episodic rhinorrhea, sneezing, obstruction of the nasal passages with lacrimation and pruritis of the nasal mucosa, conjunctiva and oropharynx are the classic hallmarks of allergic rhinitis [6]. Nasal congestion, post nasal drip, repeated sneezing and nasal discharge have been reported as the most bothersome symptoms of allergic rhinitis by patients [8].

Under normal conditions, the nose contains a large mucosal surface area through the folds of the turbinates that accounts for 50 to $65 \%$ of resistance to airflow in the airway [9]. It serves to adjust the temperature and moisture content of inhaled air and to filter out particulate matter greater than 10 micrometers in size [10]. This occurs by impingement in the submucosal layer, consisting of mucous, seromucous and serous glands. Ciliary action moves the entrapped particles and partial enzymatic degradation occurs in the mucosal layer [6].

In allergic rhinitis, this impaction and partial degradation of inhaled aeroallergens causes an IgE-mediated reaction [11]. The initial interaction occurs between the allergen and intraepithelial mast cells and then proceeds to involve deeper perivenular mast cells, both of which contain allergen- specific IgE on their cell surface [11]. During symptomatic episodes (e.g. seasonal exacerbations) the already swollen mucosa is hyperaemic and allows for enhanced penetration of both inciting and unrelated allergens. Over time, symptoms of rhinitis occur on exposure to lower doses of allergen (priming phenomenon) and non specific irritants (hyper-reactivity) leading to propagation of symptoms [12]. Ongoing background allergic reactivity has been shown to be a major influence on symptoms of allergic rhinitis in susceptible patients and both 'pre-priming' (non-specific exposure) and 'priming' (enhanced exposure) account for the increasing burden of allergic disease in an individual [13]. Examples of irritants that may be related to an increase in allergic symptoms are environmental tobacco smoke and air pollution [14].

Upon anterior rhinoscopy, patients with allergic rhinitis demonstrate pinkish grey pale, boggy mucosa covered with a thin glistening mucous [15]. Nasal mucosal biopsies from sensitized individuals show edema and infiltration by eosinophils along with basophils and neutrophils [6]. Mast cells in this region generate and release mediators through IgE dependant reactions that produce tissue edema and eosinophilic infiltration which manifests as nasal pruritus and symptoms of obstruction [11].

Long standing nasal obstruction and itching of the nose can lead to repeated manipulation of the external nares causing excoriation as well as a permanent transverse hyperpigmented or hypopigmented crease extending across the junction of the lower and middle thirds of the nasal bridge. This occurs at the site of the natural crease of the skin that is produced when the tip of the nose is pushed up with the hand (the "allergic salute") and a consequent transverse nasal crease [16]. This nasal line can vary from a faint marking to an atrophic scar seen in older patients with chronic symptoms [17].

Post-nasal drip is another common symptom of allergic rhinitis, which occurs when excess mucous produced by the nasal mucosa accumulates in the posterior pharynx and leads to cough, constant swallowing or halitosis [18]. Adults and older children will frequently blow their noses, but young children who lack this ability, will often snort, sniff or cough to clear additional mucous. Some may also produce a clicking noise known as the 'palatal click' due to itching of the palate with the tongue [18].

Nasal polyps occur in about $5 \%$ of individuals with allergic rhinitis [19]. Polyps represent mucosal protrusions containing edema fluid with variable numbers of eosinophils and can increase obstructive symptoms [19]. Polyps can concurrently arise within the nasopharynx or sinuses [20]. Patients with nasal polyps often suffer from more profound chronic nasal congestion, and are also affected by hyponosmia or anosmia and in advanced cases, dysguesia [20]. It is uncommon for children with allergic rhinitis to have nasal polyposis and alternative etiologies should be sought for nasal obstruction in this age group [21]. Long standing allergic rhinitis has been shown to result in nasal mucosal tissue remodeling [22].

Bacterial sinusitis can complicate allergic rhinitis due to obstruction of the sinus osteomeatal complex [23]. Symptoms of bacterial infection include fever, purulent nasal discharge, facial pain and pressure, toothaches and malaise [24]. In a mouse model of allergic rhinitis, a heightened inflammatory response was seen with ongoing allergic inflammatory responses in those mice that were sensitized to have allergic rhinitis with a superimposed bacterial infection vs. a control group with infection alone [25]. This suggests that concomitant allergic disease can worsen symptoms of bacterial infection [23].

As allergic rhinitis generally presents in a typical symptom complex as described above, uncharacteristic presentations should prompt clinicians to search for alternative diagnosis. Important features indicating an alternative diagnosis can include unilateral symptoms, isolated nasal obstruction without other symptoms, mucopurulent rhinorhea and post nasal drip with thick mucous and anterior rhino rhea with pain, recurrent epistaxis and anosmia [21,24]. Although variations of presentations are not uncommon, additional work up to rule out other etiologies and secondary disease processes may be warranted [2]. Table 1 indicates other potential diagnoses to consider if any of these features are present $[7,26]$.

\section{Clinical Manifestations and Comorbidities}

Depending on the patient's age at presentation, the consequences of long standing allergic rhinitis may vary. Patients may be chronic mouth breathers with long standing nasal congestion and children 


\begin{tabular}{|c|c|}
\hline Differential Diagnosis of Allergic Rhinitis & Red Flag Symptoms \\
\hline Nasal tumors & Unilateral symptoms, +/- visual changes, lack of nasal itch, lack of sneezing, recurrent epistaxis. \\
\hline Wegner's Granulomatosis & Epistaxis, recurrent sinusitis, pulmonary involvement, hematuria, systemic symptoms \\
\hline Sarcoidosis & Associated hilar adenopathy, occasionally pyoderma gangrenosum. \\
\hline Viral rhinitis & $\begin{array}{l}\text { Nasal obstruction and congestion, infections are self-limiting and will resolve with or without treatment of } \\
\text { symptoms (acute) }\end{array}$ \\
\hline Vasomotor rhinitis & $\begin{array}{l}\text { Perennial symptoms of congestion, hypersecretion, pruritus and/or sneezing associated with temperature } \\
\text { changes, humidity, ingestion of spicy food or alcohol, and odors. }\end{array}$ \\
\hline Hormonal or drug-induced rhinitis & $\begin{array}{l}\text { May be associated with pregnancy, oral contraceptive use, or hypothyroidism. Medications associated with } \\
\text { triggering symptoms of rhinitis include ACE inhibitors, reserpine, guanethidine, phentolamine, methyldopa, } \\
\text { prazosin, beta blockers, chlorpromazine, topical nasal decongestants, aspirin, and nonsteroidal anti-inflamma- } \\
\text { tory drugs. Difficult to diagnose, but may resolve after delivery, or hyperthyroidism treatment. }\end{array}$ \\
\hline Nonallergic rhinitis with eosinophilia syndrome & $\begin{array}{l}\text { Congestion and nasal eosinophilia with no obvious allergic source. Negative skin testing and/or RAST. May be } \\
\text { associated with non- IgE-mediated asthma, aspirin intolerance, and nasal polyps. A subtype of this condition } \\
\text { is blood eosinophilia nonallergic rhinitis syndrome. It is unclear whether these two conditions differ from other } \\
\text { non- allergic rhinitis syndromes or if they are simply variants of allergic rhinitis without identifiable allergens. }\end{array}$ \\
\hline Bacterial rhinosinusitis & Nasal obstruction, fever, facial pain, worsening of symptoms without treatment (chronic). \\
\hline Occupational rhinitis & Triggered by a chemical or irritant in the occupational environment. \\
\hline Structural or mechanical conditions & Choanal atresia, deviated septum, enlarged adenoids, foreign bodies, hypertrophic turbinates \\
\hline
\end{tabular}

Potential Differential Diagnoses, adapted from Bousquet et al. [7] and Quillen et al. [26].

Table 1: Potential Differential Diagnoses.

with early-onset allergic rhinitis may develop "allergic facies" [27]. This typical appearance manifests as a high arched palate, open mouth due to mouth breathing and dental malocclusion [27]. Discoloration of lower orbitopalpebral grooves in children is not an uncommon stigma of perennial allergic rhinitis [15]. The more severe the allergic disease early on, often the more pronounced the discoloration. These "allergic shiners" are due to venous stasis and infraorbital edema and are not seen in children with uncomplicated seasonal disease [15]. In severe cases, the mucous membranes of the eyes, Eustachian tube, middle ear and paranasal sinuses may be involved [23]. This produces conjunctival irritation, hyperemia and lacrimation. Patients may experience ear fullness and popping and itching of the palate.

Many other conditions are associated with allergic rhinitis including asthma, allergic conjunctivitis and atopic dermatitis [28]. Asthma is defined as a chronic inflammatory disease of the airways characterized by paroxysmal or persistent cough, chest tightness, wheezing and shortness of breath [29]. Episodes of airway hyperresponsiveness are generally associated with widespread airflow obstruction in the lungs and occur with exposure to allergens or irritants [30]. Symptoms characteristically worsen at night and typically abate spontaneously or with specific treatments [30]. A history of other atopic disease, particularly allergic rhinitis is helpful in identifying patients with asthma. Common triggers that should be identified include dust mites, cockroaches, animal dander, moulds, pollens, exercise and exposure to tobacco smoke or cold air [29]. Other comorbidities that can aggravate asthma include sleep disordered breathing, gastroesophageal reflux disease and chronic obstructive pulmonary disease [29]. The physical exam in asthmatic patients can be unremarkable but may include variable degree of wheezing, indicative of airflow obstruction. Concomitant search for features of other atopic disease (i.e. eczema, nasal turbinate hypertrophy or mucosal edema) should be sought [30].

Allergic asthma and allergic rhinitis are often considered clinical manifestations of the same condition, the chronic allergic respiratory syndrome [31]. The 'one airway' hypothesis has been proposed suggesting that the upper and lower airways do not function as anatomically or functionally distinct areas [32]. Epidemiologic surveys have shown that allergic rhinitis and asthma commonly coexist and that patients with nasal allergy demonstrate nonspecific bronchial hyper-responsiveness in the absence of overt asthma [33]. Bronchial inflammation can result from nasal allergen challenge in patients with $\mathrm{AR}$ in the absence of obvious asthma [21,32]. As well, patients with asthma can have eosinophilic infiltration of their nasal mucosa without reporting symptoms of rhinitis [21,32]. The ARIA report was a key milestone publication clearly indicating the link between allergic rhinitis and asthma and offered up-to-date evidenced based treatment guidelines for the effective co-management of these closely related conditions [7].

Allergic conjunctivitis typically manifests as itching, tearing, conjunctival edema, hyperemia, watery discharge and photophobia [34]. It is classified as either seasonal allergic conjunctivitis or perennial allergic conjunctivitis and is often diagnosed concurrently with allergic rhinitis or referred to as single entity, allergic rhinoconjunctivitis [34].

Up to $80 \%$ of children with atopic dermatitis will later develop allergic rhinitis or asthma later on in life [35]. It has been found that atopic dermatitis, also known as 'eczema', is often the first manifestation of atopic disease in genetically predisposed individuals [35]. Atopic dermatitis is also considered the beginning of the so-called "atopic march", the recognized tendency to first develop atopic dermatitis, followed by food allergy and then either asthma or allergic rhinitis [36] Atopic dermatitis manifests in the first year of life in $60 \%$ of cases and $85 \%$ of cases by 5 years of age [36]. It presents as dry, pruritic skin, most commonly in the flexural distribution in children initially (neck, antecubital fossa and popliteal fossa) and can progress to become "the itch that rashes" [37]. This is the recognized tendency for atopic dermatitis to become a chronic, relapsing skin condition, as in response to pruritis, a primordial reaction leads to frequent scratching, which in turn triggers acute excoriations or chronic lichenification [37]. In adulthood eczema mostly commonly occurs on hands, forearms, face and feet in a lichenified, excoriated papular form [38].

Duration of rhinopathy, severity of symptoms and associated conditions all impact on the presentation of allergic rhinitis, including both nasal and non-nasal features [7]. When diagnosing allergic rhinitis, clinicians should carry a high index of suspicion for related co-morbidities [24].

\section{Quality of Life}

The introduction of various quality of life tools and questionnaires 
has allowed better assessments of the impact of illness on patient's lives with allergic rhinitis. The Rhinoconjunctivitis Quality of Life Questionnaire (RQLQ) and its adaptations (Adolescent Quality of Life Questionnaire and Pediatric Quality of Life Questionnaire) are some of the most widely used disease-specific questionnaires with respect to symptoms of allergic rhinitis, and are utilized to assess Health-Related Quality of Life (HRQL) [28].

Several epidemiological studies have shown the overall reduction in quality of life in patients suffering from allergic rhinitis $[39,40]$. Symptoms of allergic rhinitis can markedly interfere with HRQL and may predispose adults and children to a variety of comorbid conditions including asthma, sinusitis, otitis media, frequent respiratory infections, and orthodontic malocclusions which may then further impact on HRQL [41]. In the Allergies and America survey, up to 52\% of patients reported that symptoms of AR affect their performance at work and patients experience a $23 \%$ loss of productivity at work when symptoms are at their worst $[42,43]$. In children, absences and poor performance caused by distraction, fatigue, or irritability have been reported. It has been estimated that in the U.S, children with allergic rhinitis miss approximately 2 million school days per year [41,43]. School difficulties in children are also related to the adverse effects of medications, such as antihistamines and decongestants [41]. These may cause drowsiness leading to impaired school performance or behavioral problems. The first generation antihistamines, which have anticholinergic properties, have particularly been implicated with impairment of vigilance and cognitive functioning [44].

\section{Conclusions}

Clinical symptoms of allergic rhinitis are often under recognized and underreported causing a delay in seeking medical attention and subsequent reduction in health related quality of life. Episodic rhinorrhea, sneezing, obstruction of the nasal passages with lacrimation and pruritus of the nasal mucosa, conjunctiva and oropharynx are the classic hallmarks of allergic rhinitis. Conditions commonly associated with allergic rhinitis include asthma, sinusitis, allergic conjunctivitis and atopic dermatitis. Long standing disease can lead to mucosal remodeling, atrophic skin changes and overall increased morbidity.

\section{Acknowledgements}

MN is supported by a Ministry of Research and Innovation (MRI) / Queen's University Post-Doctoral Fellowship award and an AllerGen Canadian Allergy and Immune Diseases Advanced Training Initiative (CAIDATI) Award.

\section{References}

1. Pawankar R, Bunnag C, Chen Y, Fukuda T, Kim YY, et al. (2009) Allergic rhinitis and its impact on asthma update (ARIA 2008)--western and Asian-Pacific perspective. Asian Pac J Allergy Immunol 27: 237-243.

2. Allergies in America Survey. Executive summary.

3. Schlesselman L (2008) Counselling Patients about Allergic Rhinitis. LebharFriedman Inc.

4. Rondon C, Fernandez J, Canto G, Blanca M (2010) Local allergic rhinitis: concept, clinical manifestations, and diagnostic approach. J Investig Allergol Clin Immunol 20: 364-371.

5. del Cuvillo A, Montoro J, Bartra J, Valero A, Ferrer M, et al. (2010) Validation of ARIA duration and severity classifications in Spanish allergic rhinitis patients The ADRIAL cohort study. Rhinology 48: 201-205.

6. (2016-2017) Harrisons Internal Medicine (17th edition).

7. Bousquet J, Van Cauwenberge P, Khaltaev N (2001) Allergic rhinitis and its impact on asthma. J Allergy Clin Immunol 108: S147-S334.

8. Stull DE, Meltzer EO, Krouse JH, Roberts L, Kim S, et al. (2010) The conges- tion quantifier five-item test for nasal congestion: refinement of the congestion quantifier seven-item test. Am J Rhinol Allergy 24: 34-38.

9. Chaaban M, Corey JP (2011) Assessing nasal air flow: options and utility. Proc Am Thorac Soc 8: 70-78.

10. Schroeter JD, Kimbell JS, Asgharian B (2006) Analysis of particle deposition in the turbinate and olfactory regions using a human nasal computational fluid dynamics model. J Aerosol Med 19: 301-313.

11. Pawankar R, Yamagishi S, Yagi T (2000) Revisiting the roles of mast cells in allergic rhinitis and its relation to local IgE synthesis. Am J Rhinol 14: 309-317.

12. Kemp AS (2009) Allergic rhinitis. Paediatr Respir Rev 10: 63-68.

13. Ellis AK, Ratz JD, Day AG, Day JH (2010) Factors that affect the allergic rhinitis response to ragweed allergen exposure. Ann Allergy Asthma Immunol 104 293-298.

14. Hersoug LG, Husemoen LL, Thomsen SF, Sigsgaard T, Thuesen BH, et al. (2010) Association of indoor air pollution with rhinitis symptoms, atopy and nitric oxide levels in exhaled air. Int Arch Allergy Immunol 153: 403-412.

15. Marks MB (1966) Allergic shiners. Dark circles under the eyes in children. Clin Pediatr (Phila) 5: 655-658.

16. Berger WE (2004) Allergic rhinitis in children : diagnosis and management strategies. Paediatr Drugs 6: 233-250.

17. Myers WA (1960) The "nasal crease". A physical sign of allergic rhinitis. JAMA 174: $1204-1206$

18. Rosenberg M (1996) Clinical assessment of bad breath: current concepts. $J$ Am Dent Assoc 127: 475-482.

19. Settipane GA (1996) Epidemiology of nasal polyps. Allergy Asthma Proc 17 231-236.

20. Thomas M, Yawn BP, Price D, Lund V, Mullol J, et al. (2008) EPOS Primary Care Guidelines: European Position Paper on the Primary Care Diagnosis and Management of Rhinosinusitis and Nasal Polyps 2007 - a summary. Prim Care Respir J 17: 79-89.

21. Skoner DP (2001) Allergic rhinitis: definition, epidemiology, pathophysiology, detection, and diagnosis. J Allergy Clin Immunol 108: S2-S8.

22. Constantino Gde T, Mello Jr JF (2009) Remodeling of the lower and upper airways. Braz J Otorhinolaryngol 75: 151-156.

23. Skoner DP (2000) Complications of allergic rhinitis. J Allergy Clin Immunol 105 S605-S609.

24. Meltzer EO, Hamilos DL (2011) Rhinosinusitis diagnosis and management fo the clinician: a synopsis of recent consensus guidelines. Mayo Clin Proc 86: 427-443.

25. Blair C, Nelson M, Thompson K, Boonlayangoor S, Haney L, et al. (2001) Allergic inflammation enhances bacterial sinusitis in mice. J Allergy Clin Immunol 108: 424-429.

26. Quillen DM, Feller DB (2006) Diagnosing rhinitis: allergic vs. nonallergic. Am Fam Physician 73: 1583-1590.

27. Settipane RA (1999) Complications of allergic rhinitis. Allergy Asthma Proc 20 209-213.

28. Thompson AK, Juniper E, Meltzer EO (2000) Quality of life in patients with allergic rhinitis. Ann Allergy Asthma Immunol 85: 338-347.

29. National Asthma Education and Prevention Program (2007) Expert Pane Report 3 (EPR-3): Guidelines for the Diagnosis and Management of AsthmaSummary Report 2007. J Allergy Clin Immunol 120: S94-S138.

30. Bateman ED, Hurd SS, Barnes PJ, Bousquet J, Drazen JM, et al. (2008) Globa strategy for asthma management and prevention: GINA executive summary. Eur Respir J 31: 143-178.

31. Togias A (2003) Rhinitis and asthma: evidence for respiratory system integration. J Allergy Clin Immunol 111: 1171-1183.

32. Slavin RG (2008) The upper and lower airways: the epidemiological and pathophysiological connection. Allergy Asthma Proc 29: 553-556.

33. Jeffery PK, Haahtela T (2006) Allergic rhinitis and asthma: inflammation in a one-airway condition. BMC Pulm Med 6: S5. 
34. Pelikan Z (2009) Seasonal and perennial allergic conjunctivitis: the possible role of nasal allergy. Clin Experiment Ophthalmol 37: 448-457.

35. Eichenfield LF, Hanifin JM, Beck LA, Lemanske RF Jr, Sampson HA, et al (2003) Atopic dermatitis and asthma: parallels in the evolution of treatment. Pediatrics 111: 608-616.

36. Hahn EL, Bacharier LB (2005) The atopic march: the pattern of allergic disease development in childhood. Immunol Allergy Clin North Am 25: 231-246, v.

37. Lewis-Jones S, Mugglestone MA, Guideline Development Group (2007) Management of atopic eczema in children aged up to 12 years: summary of NICE guidance. BMJ 335: 1263-1264

38. Darsow U, Wollenberg A, Simon D, Taïeb A, Werfel T, et al. (2010) ETFAD/ EADV eczema task force 2009 position paper on diagnosis and treatment of atopic dermatitis. J Eur Acad Dermatol Venereol 24: 317-328.

39. Schoenwetter WF, Dupclay L Jr, Appajosyula S, Botteman MF, Pashos CL (2004) Economic impact and quality-of-life burden of allergic rhinitis. Curr Med Res Opin 20: 305-317.
40. Meltzer EO, Gross GN, Katial R, Storms WW (2012) Allergic rhinitis substantially impacts patient quality of life: findings from the Nasal Allergy Survey Assessing Limitations. J Fam Pract 61: S5-S10.

41. Meltzer EO (1990) Antihistamine- and decongestant-induced performance decrements. J Occup Med 32: 327-334.

42. Nathan RA, Meltzer EO, Derebery J, Campbell UB, Stang PE, et al. (2008) The prevalence of nasal symptoms attributed to allergies in the United States: findings from the burden of rhinitis in an America survey. Allergy Asthma Proc 29: $600-608$

43. Meltzer EO, Blaiss MS, Derebery MJ, Mahr TA, Gordon BR, et al. (2009) Burden of allergic rhinitis: results from the Pediatric Allergies in America survey. $J$ Allergy Clin Immunol 124: S43-S70.

44. Wilken JA, Kane RL, Ellis AK, Rafeiro E, Briscoe MP, et al. (2003) A comparison of the effect of diphenhydramine and desloratadine on vigilance and cognitive function during treatment of ragweed-induced allergic rhinitis. Ann Allergy Asthma Immunol 91: 375-385.
This article was originally published in a special issue, Allergic Rhinosinusitis handled by Editor(s). Reginald F. Baugh, University of Toledo, USA. 